\title{
Family makeover: Coaching, confession and parental responsibilisation
}

\author{
Magnus Dahlstedt and Andreas Fejes
}

\section{Linköping University Post Print}

\section{Tweet}

N.B.: When citing this work, cite the original article.

This is an electronic version of an article published in:

Magnus Dahlstedt and Andreas Fejes, Family makeover: Coaching, confession and parental responsibilisation, 2014, Pedagogy, Culture \& Society, (22), 2, 169-188.

http://dx.doi.org/10.1080/14681366.2013.812136

Copyright: Taylor \& Francis (Routledge)

http://www.routledge.com/

Postprint available at: Linköping University Electronic Press

http://urn.kb.se/resolve?urn=urn:nbn:se:liu:diva- 88512 


\title{
Family Makeover: Coaching, Confession and Parental Responsibilisation
}

\author{
Magnus Dahlstedt \& Andreas Fejes
}

REMESO, Linköping University, Sweden

\author{
Department of Behavioural Sciences and Learning, Linköping University, Sweden
}

\begin{abstract}
Today, there is a widespread idea that parents need to learn how to carry out their roles as parents. Practices of parental learning operate throughout society. This article deals with one particular practice of parental learning, namely nanny TV, and the way in which ideal parents are constructed through such programmes. The point of departure is SOS family, a series broadcast on Swedish television in 2008. Proceeding from the theorising of governmentality developed in the wake of the work of Michel Foucault, we analyse the parental ideals conveyed in the series, as an example of the way parents are constituted as subjects in the 'advanced liberal society' of today. The ideal parent is a subject who, guided by the coach, is constantly endeavouring to achieve a makeover. The objective of this endeavour, however, is self-control, whereby the parents will in the end become their own coaches.
\end{abstract}

Keywords confession; parent education; governmentality; citizenship; nanny TV; responsibilisation

\section{Introduction}

Programs for parent education and parent coaching have become a conspicuous part of contemporary society (cf. Gillies 2005; Widding 2011). Parents are positioned as being in need of learning in order to be able to carry out their roles as parents, either through educational practices or through coaching and learning in everyday life (Dahlstedt 2009a). Learning to become a parent can thus be seen as a practice of lifelong learning (cf. Assarsson and Aarsand 2011). The parent of today needs to be a pedagogical parent (Popkewitz 2003), and such a parent is construed through both educational and everyday practices. This article will deal with one such everyday practice, namely nanny television and how ideal parents are constructed through such programmes.

Nanny television is part of popular culture. Such culture teaches us a lot about the society we live in. Within popular culture, ideas, ideals and visions are compared and contrasted with one another. The Swedish TV listings contain a large number of TV productions that in one way or another open up people's lives and lifestyles to public view, that turn everyday life into an object for the scrutinising gaze of the viewing public. In popular discourse, as well as in the field of media and cultural studies, productions of this type have over recent years come to be referred to as reality TV (Palmer 2003; Andrejevic 2004), a broad genre which comprises a range of different types of production; from more traditional documentaries to various types of occupational documentary, in which the viewer gets to follow individuals from a range of different occupations 'behind the scenes' in their everyday working lives; from celebrity soaps to police and detective series; from traditional advice, cooking and gardening shows to a range of variations on the makeover theme, in which participants are given some kind of help to 'reinvent themselves' or some aspect of their lives.

The desire for makeovers reflected in these programmes covers more or less every single area of our lives, appearance, home and garden, sex and partnerships, pets, neighbourly (dis)harmony, illnesses, finances, working life and career, weight problems, exercise and health, education, childrearing and family life. The makeover programmes contain an underlying prompting towards 'good behaviour', directed not only at those who participate in the programmes, but also at the viewers: Follow the advice of the coach/expert, transform yourselves and you will be rewarded with success and happiness in life! 
In this article, we will be focusing on one very particular type of makeover TV, namely nanny TV. The focus of nanny TV programmes is on changing the everyday life of families. In the programmes, there is a nanny coaching the parents in how to think and behave as parents. Such parent coaching constitutes a forum for the exchange of ideas, ideals and techniques relating to parenting. This type of coaching may be viewed as a technique of parental education, whereby parents learn how to behave as 'responsible parents'. In this sense, parent coaching reflects prevailing ideas about how individual parents should think and live in order to be(come) good parents. This article analyses one of the many forms of parent coaching on offer, namely SOS family, a Swedish TV series that was broadcast on the Swedish TV3 channel in the autumn of 2008. The specific aim is to analyse how good parents are constructed through the program.

Drawing on the later work of Michel Foucault (1998, 2007), our analysis directs attention towards technologies of power and technologies of the self in order to understand how subjects are created. What values, abilities and qualities characterise the 'good parent' in this TV series? In relation to what is the parental ideal defined? How is 'good parenting' fostered in the TV series? What does this ideal tell us about the present time? In the following, we will introduce our analytical perspective in more detail before moving on to a contextualisation of parent coaching as a phenomenon. We then present the TV series in more detail, the idea behind the show and the structure of the series itself, followed by a more detailed analysis of a single episode from the series. The central points in the analysis are then finally related to a series of challenges and developmental trends that characterise the 'advanced liberal' contemporaries.

\section{Analytical Perspective}

The point of departure for this article is the theorising of subject-creation, power and governance that has developed in the wake of the work of Michel Foucault (cf. Rose 1999). In education, Foucault began to be taken up to a larger extent in the 1990s. On a general level, a movement from a focus on Foucault's writing on disciplinary power and dividing practices to a focus on his later work on governmentality (cf. Fejes 2008a, 2008b; Dahlstedt 2009a; Olssen 2008; Simons and Masschelein 2008) and technologies of the self (cf. Besley and Peters 2007; Fejes 2010, 2011; Fejes and Dahlstedt 2012) can be identified.

In this article, we will draw on the later work of Foucault in order to analyse how the ideal parent is constructed in nanny TV. Foucault (1988) differentiates between technologies of power and technologies of the self. While technologies of power 'determine the conduct of individuals and submit them to certain ends of domination', technologies of the self relate to people's self-formation and the way they produce themselves as citizens. These techniques 'permit individuals to effect by their own means or with the help of others a certain number of operations on their own bodies and souls, thoughts, conduct, and way of being, so as to transform themselves in order to attain a certain state of happiness, purity, wisdom, perfection, or immortality' (p. 18). We will specifically draw on the technology of confession in our analysis (cf. Fejes \& Dahlstedt 2012).

Confession was one of the technologies of the self, studied by Foucault (2003). He argued, that with the emergence of Christianity purity of the self became a priority. In order for purity to emerge, everyone had a duty to know who she was, to search oneself and acknowledge one's faults, to recognise temptations, and to locate desires. Knowledge of the self emerged through disclosure the self either to God, the priest or to the others in the community. Disclosure of the self was conducted through the technique of verbalization. However, purity could not emerge unless disclosure was combined with a renunciation of ones self, which was carried out through practices of verbalised drama (for a further elaboration, see Fejes \& Dahlstedt 2012). Such practices of confession continued until the $17^{\text {th }}$ Century. However, as 
argued by Foucault (2003), the relationship between the disclosure of the self and the verbalised renunciation of the self is important throughout Christianity. However, today, he argued, verbalisation has become the most important action.

From the eighteenth Century to the present, the techniques of verbalization have been reinserted in a different context by so-called human sciences in order to use them without renunciation of the self but to constitute, positively, a new self. To use these techniques without renouncing oneself constitutes a decisive break.

(Foucault 2003, 167)

Thus, in contemporary times, we can see how confession has become linked to science and thus has become scientised 'through clinical codifications, personal examinations, histological techniques, the general documentation and data collection of personal data, the proliferation of interpretative schemas and the development of a whole host of therapeutic techniques for "normalization"" (Besley and Peters 2007, 16). Verbalisation has become linked to science and reinvented as a 'scientific' practice that promises to help us live a better life. This scientisation construes confession as an interface between the public and private domains where confession always requires an other, either real or virtual, to whom one confesses (cf. Foucault 1998).

The formation of citizens constantly changes and reappears in new forms. In the 'advanced liberal' society, governance is based on the principle of responsibilisation, i.e. the constitution of citizens as free and responsible subjects, responsible for creating their own lives on the basis of their own ideals, circumstances and ambitions (Rose 1999). The formation of citizens involves not only the upcoming generation, i.e. children and youths, but also their parents. In order to enable parents to raise children and youth in the 'desired' direction, they also need to be educated as parents (Dahlstedt 2009a). Interventions in the one direction or the other therefore cannot easily be distinguished from one another; they are intimately woven together in a complex 'government through the family' (Donzelot 1977, 92). Thus, to a large extent, society is governed through the family.

\section{Parenting, Media and Reality TV}

There is a wide range of literature which deals with the formation of parents and parental ideals, for instance, analysing public policies in terms of parental education programmes (Gleichmann 2004; Gillies 2005; Danielsen and Mühleisen 2009; Widding 2011). Here, studies have shown that in such programmes there is a formation of an ideal 'good parent', based on the normalisation of certain representations and categorisations in terms of gender, class and race/ethnicity (Gleichmann 2004; Gillies 2005). These parental ideals mirror other current ideals in society relating to citizenship, government and the relationship between the individual and the state, which are in a state of constant flux. For instance, in line with the political shifts that have taken place in Sweden since the 1980s, parental education programmes have become, increasingly, shaped by neo-liberal ideals:

The welfare of the family is based, to a large extent, on its members being able to live up to the demands of self-regulation, and on the parents being capable of assessing and regulating their own "assistance needs", i.e. being able to help themselves from the range of social welfare services or local networks of support that are available (Gleichmann 2004, 257).

Other studies have shown that there is an increasing interest regarding issues of parenting in the media and popular culture. This takes the form, for example, of a large number of parent- 
ing handbooks, magazines and nanny TV programmes (Johansson 2006, 2007; Lunt 2008; Assarson and Aarsand 2011). Studying the importance of media and popular culture in the formation of 'good parenting' is particularly important in today's society, where 'the media become more deeply integrated into everyday life' (Livingstone 1993, 5). Thus, the media and popular culture become increasingly important for learning, for individuals as well as families, and parents as well as children (Morley 1986; Illouz 2003; Assarson and Aarsand 2011). In nanny TV programmes, such as Supernanny and Nanny 911, there is an ongoing circulation of 'strategies for informal learning through the acquisition of guidelines and strategies' (Ouellette and Hay 2008, 97), whereby the viewers can learn how to become 'good parents'.

These shows are part of the broad genre of reality TV, which has recently attracted the attention of a large number of scholars (Palmer 2004; Aslama and Pantti 2006; Ouellette and Hay 2008; Winslow 2010). One of the characteristics of productions within this particular genre is that they appear to visualise reality as it is, giving the viewers the opportunity to take part in the lives of the 'ordinary people' depicted, to hear these people talking in front of the camera, seemingly directly to the viewers (Aslama and Pantti 2006). Reality TV productions usually make matters that have previously been considered as 'private' into a public affair, making virtually anything visible to the viewer (Palmer 2003).

Scholars drawing on a Foucauldian framework have approached the phenomenon of reality TV, and popular culture more widely, in terms of governing (cf. Palmer 2003; Andrejevic 2004; Heyes 2007; Ouellette and Hay 2008; Lewis 2008). Among these scholars, Jack Z. Batich (2007, 6-7) argues that reality TV is 'less about representing reality than intervening in it; less mediating and more involving'. This means that, watching TV is not just about taking part in a certain set of stories or representations of society. Rather, watching TV is about involving the viewers in a learning process, where they discover how it is possible, or desirable, to behave as a parent, citizen, partner or any other kind of subject. In this sense, following Laurie Ouellette and James Hay $(2008,2)$, reality TV is concerned with governing society:

...reality TV simultaneously diffuses and amplifies the government of everyday life, utilizing the cultural power of television (and its convergence with books, magazines, the web, and mobile media) to assess and guide the ethics, behaviors, aspirations, and routines of ordinary people.

What can we see then, by studying a phenomenon such as nanny TV programmes? A programme such as SOS family forms and mobilises a set of parenting ideals, conveying prevailing expectations of what it is to be a 'good parent'. In one way or another, these expectations can be said to contribute to the self-realisation of parents, as the shows also offer the viewers a range of techniques as to how to think and behave in order to become a 'good parent'. Viewers are, in various ways, invited to reflect about their own role as parents (Lunt 2008), and in what way their own thoughts and actions fit the particular normality, as defined by the nanny or coach (Palmer 2004; Heyes 2007; Morreale 2007).

\section{The Outline of the Programme}

The television series SOS family is a Swedish version of high-rating nanny programmes such as the British Supernanny and the American Nanny 911, several series of which have been broadcast on Swedish TV over recent years. The coach in SOS family, Annelie Arrefelt, participated in 2005 in a similar TV series, Nanny on call. We have followed the entire first series, which was aired on the TV3 channel in the autumn of 2008. In total, the series comprised ten episodes. Each episode is 40 minutes long.

In this article, we will focus, in particular, on the first episode of the series. By focusing on a particular episode it becomes possible to do a more in-depth analysis of the coaching and 
parenting technologies mobilised, compared to examining the series in its entirety. Although the families appearing in the ten episodes differ, as does the specific content of each episode, there are still a number of similarities between each episode, particularly in terms of their structure and dramaturgy, and the way in which 'family problems' are presented and 'solutions' are addressed. In this context, it is particularly interesting to study the very first episode of the series, as it introduces the viewers both to the programme as a concept and to its dramaturgy. With respect to its design, dramaturgy and framing, the first episode is similar to the other episodes in the series.

In each episode, the viewers follow a family who are in need of guidance and help in coping with their family situation. In the first episode, the family comprises mum, Madeleine, step-dad, Rickard, and two teenagers, Yasemin and Deniz. In this family, a somewhat dysfunctional relationship between the mother and the daughter is presented as the main problem. Thus, the drama in the episode primarily revolves around the relationship between mum, Madeleine, daughter, Yasemin, and the coach, Anneli. Among these characters, the coach plays the lead. In the role of expert, she is the one taking the initiative and making changes in the family. According to the main story told in this episode, the mum's problem in setting limits and getting the daughter to respect these limits, leads to continuous tensions in family life, not least when it comes to sleeping habits and schooling.

Even though the content of each episode varies, the series follows a uniform narrative logic. Each episode can be divided into four parts. In the first part, the family is presented and the viewer is introduced to the family's specific problems or conflicts. In the second part, the coach is introduced and the problem or conflict is illuminated by showing the coach as they accompany the family through an ordinary day. In the third part, the coach actively intervenes in family life by giving tips and advice to the parents, i.e. coaching put into practice. In the fourth and final part of the episode comes the resolution where the viewer is shown the results of the coach's interventions. One could say that, in somewhat simplified terms, the programme allows the viewer to see how both the parents and the families, as a whole, undergo a linear process of makeover or transformation, from problems to normal function, from chaos to peace and harmony, from irresponsible to responsible, non-independent to independent, guided by the coach. The contrasting of before and after constitutes a dramaturgic device that is very common in makeover and other reality TV productions (Illouz 2003; Bratich 2007; Winslow 2010).

The episodes weave together a series of discursive elements into a multi-layered narrative; there are flashbacks, music and background images; throughout each episode the voice of the narrator guides the viewer through family life, not least by introducing the different characters and binding the different parts of the episode together into a coherent story; there are documentary glimpses showing the family's everyday life; there are interviews with the coach and the participants, but usually the coach and the participants talk freely, without answering specific questions; there are interactions between the coach and the participants, where coaching is put into practice.

In the following section, the makeover or self-realisation of the parents is analysed on the basis of a number of sequences drawn from the first episode of the SOS family series. Our analysis is connected with previous studies on similar topics. By focusing on one TV programme and, more specifically, one episode, we will contribute with descriptions of how power operates in the programme in more detail. Such descriptions are important as they contribute to the work towards opening up a space in which to alter the discussion about nanny TV programmes and what they do in terms of power, i.e. shaping subjectivity (cf. Fejes and Dahlstedt 2012).

\section{Therapeutic Interventions}


According to some researchers, the genre of reality TV has contributed to challenging conventional forms of authority and expertise (Livingstone 1993; Taylor 2002). Having analyzed the whole SOS family series in more detail, we would concur with these researchers, at least to some extent. The series invites the viewers to learn more about how problems in the family can be resolved. It provides a toolkit that the viewers may then choose to apply in their own everyday lives. In this way, the individual is created as an expert in her own right. That is to say, the show makes tools available; their use is not compulsory. On the other hand, Annelie Arrefelt is presented in a way that emphasises pointedly the authority of the coach. In the second part of the episode, where the coach is introduced to the viewers for the first time, the narrator describes coach, Anneli, as follows:

Annelie Arrefelt is an expert on children and parents. She is an educationalist with an extensive background in child and youth issues. She works successfully with youths who have burnt their bridges to society and with crisis counselling for the families of young children. She takes on clients for a short, intensive period, and sorts out their problems using a range of measures. It is often the behaviour of the parents that takes longest to change. For many families, the meeting with Annelie provides a rescue. She refuses to see anyone as a hopeless case. She sees only possibilities in those she works with.

The coach's role as 'expert' is an important part of the concept behind the series. The coach constitutes a kind of hero, a knight in shining armour: 'For many families, the meeting with Annelie provides a rescue'. The task involves, in a short space of time, changing the family's behaviour and providing tools that will enable the family to resolve its problems. Throughout the series, it is the expert who is in the privileged position to distinguish normality from deviance, to define the problems in the family, the solution to these problems as well as the conditions for implementing these solutions.

In the series as a whole, there is a consistently strong focus on emotions. The shows devote a large proportion of their time to teaching the participants various ways to deal with, talk about and reflect on emotions. The series appears in other words, like many other realityproductions, to be framed by a kind of therapeutic worldview, which focuses on the individual and her emotional state, frustrations, anxiety, stress, self-confidence, motivation and selfrealisation (Furedi 2004; Aslama and Pantti 2006). In line with this particular worldview, the coaching working method is described as an endeavour to see possibilities rather than difficulties and problems for as long as possible, to focus on the positive and avoid getting stuck in negative trains of thought. The central view here is that all parents and families can change all they need is to be helped along the way, i.e. the right guidance. In other words, the focus is on a dialogue between the coach and those who constitute the object of her intervention.

The role of the coach, in this case, is that of an expert whose task is to deal with the subjects' anxiety and help them to reach the goals they have established (cf. Rose 1999). In this case, the goal is to create a more harmonious family dynamic. The coach's function is twofold. On the one hand, the coach should offer advice which it is possible for the individual to follow, but it is the individual's own responsibility to make the decision whether or not to follow the advice, i.e. the individual is responsible for their own destiny and the choices which they make. The coach does nothing more than support them in their chosen course of action. On the other hand, the coach is in a position where they can distinguish between what is normal and abnormal and, as a consequence, dividing practices are created in which the individual and the viewer can learn what constitutes normal behaviour and what does not. This example illustrates how there are technologies both of power and of the self at play, simultaneously; one does not rule out the other, rather they are intertwined or operate in parallel, which is further illustrated in the next example. 
After having introduced the coach for the first time, the narrator goes on to inform the viewers that 'Annelie will spend a day with the family in order to work out what needs to be done in order give Yasemin the possibility of having a future'. During her first day with the family, the coach attentively follows every step taken by the family members, and listens intensely to every word they utter. In this way, the series has the character of a far-reaching surveillance of the inner life of the family, a process that also involves the viewer (Andrejevic 2004), 'which leads the individual to reflect on their own behaviour' (Lunt 2008, 541). Firstly, the family members, as subjects, are objectified, compared, assessed and constructed in relation to the norm, i.e. a dividing practice. Secondly, this picture is offered to the viewers, who are able to see how the coach follows the movements of the family members, how she stands to one side, observing. In longer sequences and in close-ups, the viewers can, themselves, follow the coach's scrutinising gaze, the facial expressions and looks with which she responds to the ways in which the relationships between the family members develop. The viewers are, thus, not only observing the drama from a position as outsiders, they are also invited to turn their gaze inwards and become part of this drama themselves, and thus compare and assess themselves in relation to what is presented as desirable and normal in terms of parenting. Through this, through a work upon the self by the self, subjectivity is shaped.

\section{Parental Responsibilisation}

In the third part of the episode, after her first day with the family, it is time for the coach to intervene in the daily life of the family. In order to make Yasemin assume more responsibility, the coach intervenes by giving mum Madeleine a wide range of tips and pieces of advice, instructions and suggestions, both on her own and in various situations involving Yasemin ('Good, you did well there', 'Be firm now', 'Now I think that...'). To begin with, however, the various interventions in the family, and particularly those towards Yasemin, work anything but smoothly. This is shown not least in a scene where the coach's affirmation goes completely off the rails. In this particular scene, Yasemin, mum Madeleine and coach Annelie are on their way to buy Yasemin an ice-cream, as a reward for 'proper' behaviour. On their way to the supermarket, Yasemin has just had enough of the coach intervening in family life and clearly shows her dissatisfaction towards Annelie.

Yasemin: It's not up to you!

Madeleine: Yasemin, you know what? It's an adult you're talking to. I've never heard you behave as badly as this towards another adult.

Yasemin: She cares too much.

Annelie: Yes, exactly. I care too much, because this is my job. I know exactly what's going to happen.

Yasemin: She's going to give me an ice-cream.

Annelie: Ha; you can go look for that ice-cream on the moon. Your behaviour ...

Yasemin: It's not up to you. You've made mum bad! You've turned her into a bad person.

Annelie: Exactly. 
In this scene, the coach is not merely following the family from a distance, but is intervening directly in the life of the family. Her interventions are met, however, with powerful opposition from Yasemin. This is not the first or only time that the coach meets opposition, similar situations occur in most of the episodes. In the first episode, however, this scene is the most explicit challenge to Annelie's authority as a coach. In this situation, she is, therefore, forced to clearly define her role as an 'expert'. She emphasises very sharply that 'this is my job' and 'I know exactly what's going to happen'. Throughout this episode, and in the series as a whole, the vocabulary is generally affirmative, focusing on giving advice and on highlighting the positive, not the negative. The affirmative vocabulary is suddenly replaced by a direct, disciplinary use of language: 'you can go look for that ice-cream on the moon'. The explicit goal of the coaching is to transform the members of the family - and particularly the mother - into being more responsible, i.e. what we may talk of as a form of parental responsibilisation. However, this transformation is made possible only on condition that it is the coach who sets the agenda on the basis of her authority or expertise within the field, her specific knowledge about and experiences of working with issues of family life and parenting. It is the coach who defines right and wrong, problems and solutions, sets the limits and defines the abnormal from the normal.

\section{The Ethos of Calculation}

In the third part of each episode, after having followed family life for one day, there is a crucial sequence where the coach presents the measures she proposes for the family. Usually, the coach presents the measures to be taken in a process of deliberation, where the family members have the opportunity to discuss the different ideas proposed by the coach, before finally signing a contract. In the first episode, the coach meets with the mother and the daughter around a table in the garden. Clips from the conversation at the table are interspersed with flashbacks to the preceding day in the family and the coach's analysis of the family's situation, presented on her own into the camera. But at the table, there is also another 'expert', Patric Stacksjö, who is introduced as a 'trained communicologist'. With his assistance, Annelie introduces a special technique or 'plan' in the family, 'token economy'.

Annelie: He has a very good, well-functioning, tried and tested plan, it's called token economy. It's about dividing up the day. I'll let him tell you all about it.

Patric: A lot of the fuss arises because you don't really know how things should be. And for that, this token economy is very good, because it's actually just like a schedule, a weekly schedule. Where you agree about what happens on the different days, what is expected of you, what you should do on the days. And on the basis of these things, you also get paid, pocket money, so to speak, and that side of it. So that a lot of this fuss, you don't like need to argue about things. You've already come to an agreement about so...

Annelie: So it's just...

Patric: Yes, that's it, and it's very good for you too Yasemin...

Yasemin: Mm...

Patric: ...that the choice is the whole time on you as a person, to choose. When you know what you have to choose between, when you know what the consequences are of not doing what is written in the token economy. 
The basic idea behind token economy can be found in a variety of different forms. Common to these different variants, however, is that they are based on the therapeutic aspiration to change the way people think and behave by reinforcing certain of these behaviours and 'extinguishing' others. The token economy is staged by means of a broad repertoire of interventions in the family. What is required is the establishment of a kind of 'contract', which the different parties are to follow. The idea is that the parties' behaviour will be met with different types of response, depending on how well these correspond with the agreement that has been struck. The contract is not negotiable: 'you don't like need to argue about things'. The chain of arguments on which the doctrine of the token economy is based is self-contradictory, however. Everything is possible, but must at the same time be made into a possibility. The objective of the contract is that it should mould a calculating subject, capable of placing the situation as it is here and now in the context of a longer perspective, reflecting on the consequences it may produce, over the longer term.

Once the rules of the token economy have been described in more detail, it is time to come to an agreement. The 'negotiation' is documented by means of repeated close-ups of those present, which scrutinize in some detail the physical bearing, gestures and facial expressions of each of them. Most marked is the sense of scrutiny or surveillance that is produced by the close-ups of Yasemin, who on several occasions looks away from the camera, hides her face in her hands and sinks down over the table. The contract is drawn up. Yasemin confirms that it is 'OK with her'. Reluctantly, but all the same, the family agrees that it will follow the guidelines laid down by the token economy. The agreement is framed as an open deliberation, but the way it is arranged - with two 'experts' and a TV camera at the table - makes it virtually impossible for Yasemin not to agree to follow the suggested principles.

\section{The Power of Confession}

As mentioned above, each episode in the series begins with a presentation of the family and its specific 'problems'. As early as in these first few moments of the first episode in the series, the viewer is presented with the type of narrative that has come to constitute something of a distinctive feature of reality TV, namely that the participants, in an act of confession, speak, apparently alone, into the camera (Aslama and Pantti 2006). In order to participate in the series, the parents in the series in a way have to disclose themselves as being failed parents, as a first step on the road to become better as a parent, i.e. moving in the direction of the current norm of 'good parenting', defined in those terms set by the therapeutic framework.

At the very beginning of the episode, apparently alone with the camera and the viewer, mum Madeleine presents the main 'problem' in the family in the following way.

Madeleine: We find it a bit difficult, me and Yasemin, to communicate with each other. Voices are often raised. Yasemin has no understanding of... neither when it comes to consequence-thinking and... I think she's become less understanding about feelings and... there's a lot that she... and that's kind of what I feel.

In other, similar sequences, the participants, in front of the camera and the viewers, describe in their own words, and reflect upon, their self-realisation as parents and children. The focus of this confessional practice is the 'makeover' that the family members are going through as a consequence of their participation in the TV show and the coaching to which they are being exposed. These practices 'render citizens more transparent than ever' (Palmer 2003, 18). By talking about oneself, one's self becomes visible to others, who can in turn then compare this self with what is viewed as normal and abnormal. These mediated confessions are based on a far-reaching exposure of the participants' reflections on their innermost dreams and problems. The confession, as a technology of the self, reaches far more than those who are physically 
present at the time of the confession itself. By witnessing the confession, framed as entertainment, the viewers can compare the participants' dreams and problems with their own. At the same time, such public confessions appear as something desirable in themselves.

It is the problem as described in the confession of mum-Madeleine that serves as the point of departure for the subsequent narrative in the episode. The sequence appears to be documentary, but is obviously staged. Since the mother's description of the 'problem' is provided before the coach steps onto the stage, it appears as though the mother is describing the situation in her own words. If we focus on the actual content of the mother's description, however, and on her choice of words - and primarily the use of the term 'consequence-thinking' - there is a striking resemblance to the language and the interpretative framework that the coach will subsequently introduce into the family. In the first episode, as well as in the other episodes in the series, the language which the coach uses is formed strongly by the main ideas and concepts of a therapeutic framework, focusing on the family members' emotions, anxieties, selfconfidence and motivation. In other words, in this episode there is a specific use of language and a specific way of describing one's problems and of finding solutions to these problems, which in part is taken up and employed by Madeleine. In the problem as described by the mother, it is emotions, understanding and communication that are in focus. On the basis of this description, it is the daughter in the family, Yasemin, who appears as the most urgent 'problem' in the family.

In another scene, in the third part of the episode, mum, Madeleine, is once again sitting alone with the camera, reflecting on an incident that has just happened in which the coaching was put into practice. 'I was almost filled with hate last Friday', she says, 'I hated my own child. It feels scary that hate and love are so close to one another'. To the sound of calm, melancholy music and pictures of Yasemin in slow motion, the mother describes her feelings, reflects upon her reactions - and upon her development as a parent.

Madeleine: It's really tough just seeing her in this condition. But at the same time I got an explanation for what it was that made her get so angry. Because I thought it was like an over-reaction, from wanting to have an ice-cream to behaving in that way, that the power struggle against me was immense. When she didn't get what she wanted, she lost the struggle and that was difficult for her. Just as difficult for me too.

Here, the act of confession is an important element in the creation of the 'good parent'. By themselves and in front of the gaze of the viewers, the parents are trained to work through and deal with both their own feelings and those of the other family members. Through the 'unceasing reflexive gaze of our own self-scrutiny' (Rose 1989, 208) a more self-conscious parenting subject is created. The coaching offers one set of interpretational models, a conceptual flora and a language for describing, interpreting and understanding what is happening in the family. With the help of the tools furnished by the coaching, mum Madeleine is able to interpret both how she herself and how her daughter Yasemin feel and react. They have given her an 'explanation for what it was that made her get so angry' - namely, the fact that 'the power struggle... was immense'. The mother has thereby adopted the language used by the coach and made it an integrated part of her understanding of herself as a parent - and of her child. What is essential here is the fact that it is one set of interpretational models that is offered, which discursively effectuates a certain type of subject.

The technology of confession also appears towards the end of this episode, in the fourth part, when it is time for the coach to say goodbye to the family. The farewell is staged as an emotional situation. Happy up-tempo music and lyrics such as 'It's a brand new world, it's a brand new day' and 'Feel alright' emphasise a generally very positive emotional atmosphere. The message is that it is a new family that the coach is taking her leave of, a different family 
from the one she took on at the beginning of the programme. The conclusion shows the positive results that the coach's efforts have produced, nothing less than a family makeover, from problem to opportunity, deviant to normal, chaos to harmony, from an orientation towards conflict to one focused on consequences. In each episode, most of the participants' behaviour and speech is presented as 'authentic', in the sense that the participants appear to act and talk freely, without following certain pre-defined scripts or answering specific questions. However, in this concluding section, there is a journalist asking each of the family members, in turn, to describe the changes that have taken place.

Journalist: How do you think this has affected you?

Madeleine: I've become stronger in my role as mother. I'm a bit more well-equipped, with a few tools and new contacts, so to speak. So it actually feels really good.

In a further confession-like speech act, mum Madeleine answers the question, affirming that she really has changed, that she has internalised the coach's tips and advice, made them her own. Breiefly, Yasemine also affirms the positive changes in the family, although not quite as overwhelmingly as her mum.

Journalist: Does it feel as if you are going in the right direction?

Yasemine: Yes... it feels as if it will be great.

The coach's role here is that of the role model. 'The coaches become role models who teach participants the ritualized sets of behaviours, rules, norms and expectations that correspond to a particular stereotype of a social class and occupation' (Morreale 2007, 98-99). At the same time, the coach becomes a role model for the viewers. As viewers we are expected to learn from the makeover that the participants have undergone, to realise 'the powers of transformation' (Bratich 2007, 19-20). The rationality of the narrative is as follows: Follow the coach's tips and advice, and you too will be successful. It is not, however, only the coach who acts the part of role model in the TV series, but rather the entire family. In some sense, the participating family functions as a live instructional example of how successful the coaching can be. The confession gives additional life and vitality to this moral.

The message is not fixed, however, but is rather open to different types of interpretation (Morley 1986). On the one hand, the viewers can identify with the family, recognize themselves, see the value of transformation in accordance with the coach's principles, get tips and advice on how they can themselves change their parenting. On the other hand, viewers can distance themselves from the family, feel that their own family is actually relatively normal by comparison and thus feel fortified and confirmed in their own role as parents (Lewis 2008). In both cases, however, the specific values and behaviours initiated by the coach are normalised (Palmer 2004; Heyes 2007).

\section{Final Remarks}

This article is a case study in which we have focused on an episode of one nanny TV programme in Sweden, aimed at shaping and fostering parents. Our specific interest has been the desire to coach parents in how to become better parents. Reality TV as parental education is an exercise aimed at entertainment rather than education. Thus, viewers are in one way not treated directly as participants in an educative process, but rather as participants in entertainment. As is argued, for instance by Bratisch (2007) and Lunt (2008), reality TV is about inviting viewers to shape reality and to reflect on their own thoughts and behaviour as parents. 
Perhaps without reflecting on it, viewers of the nanny programme are, thus, invited to shape and improve themselves as parents (cf. Andrejevic 2004). Our ambition has been to, by descriptions of how power operates, contribute to the work towards opening up a space in which to alter the discussion about what nanny TV does to our subjectivities.

We have analysed the series SOS family, with a specific focus on the first episode of the series, where the concept of the series for the first time is introduced to the viewers. In this episode, as through the whole program series, a wide range of coaching techniques is mobilized in an on-going process of teaching parents (as well as children) how to become responsible subjects. Here, there is a normalization of a certain kind of parental subject. The 'ideal parent' presented in the program series is characterized primarily by its ability to calculate (i.e. to make choices and to reason about the different consequences of each choice), its sense of responsibility (i.e. to take responsibility for the consequences of the choices made) and its willingness to change. The 'ideal parent' appears as a subject, guided by the coach, constantly endeavouring to achieve a makeover. The objective of this endeavour towards makeover, however, is a form of self-control, whereby the parents will in the end become their own coaches. In order to become their own coaches, however, constant guidance is required.

The various coaching techniques initiated are very much about making the participating parents learn to become good parents by becoming 'aware' of their suggested 'shortcomings' as parents, in order to evoke a desire among the parents to gradually change their parenting role. With this change, the parents will - in turn - be more able to foster their children according to what is referred to as desirable and normal in the series (i.e. having the ability to calculate, taking responsibility and being willing to change) (cf. Assarsson and Aarsand 2011). Similarly to what has previously been found in other studies of reality TV shows (Lunt 2008; Ouellette and Hay 2008), the parental coaching in SOS family is comprised of a broad repertoire of techniques, including both technologies of power (regulating, setting limits, making demands, surveillance) and technologies of the self (motivating, making one's own choices, working on and reflecting about oneself) (cf. Foucault 1988). Among these techniques, confession is given a prominent role in the show. Becoming one's own coach requires encouragement and the ability to learn to speak about oneself to others and to oneself. In the TV show, this is expressed specifically in the way the participants (parents as well as children) speak to one another and to the coach, but also to 'invisible' others, represented by the television viewer. This encourages the formation of a will to evaluate and expose one's self, to reflect openly about one's experiences of and feelings about family life, about problems, challenges and possibilities for change. For the viewer, the message is the same - scrutinize yourself and your family, compare yourself with the ideal that the coach describes in the show, see if you need to be improved and do it by talking about yourself! Activate yourself and take responsibility!

What the program illustrates is how it is part of a wider will to govern and shape citizens (cf. Fejes and Dahlstedt 2012; Rose 1999). Through nanny TV the family in question, but also viewers, are being shaped and fostered, which is similar process to that seen in other reality TV programmes (cf. Palmer 2003; Andrejevic 2004). Through technologies of power and technologies of the self, viewers are normalised and invited to assume responsibility for improving themselves (cf. Foucault 2007). Such technologies create two different expert positions. On the one hand, the nanny expert who is deciding what is normal and what is abnormal, and who is held up as the role model for good behaviour (cf. Bratisch 2007; Morreale 2007). On the other hand, the viewer, and the family members are invited to become experts themselves, i.e. to learn certain techniques, which they themselves can use in the future in order to shape themselves into 'good parents'. In line with the argument of Livingstone (1993) and Taylor (2002), this reconfigures and challenges the conventional form of authority and expertise. Each and every individual should become his or her own expert. In other words, 
there is no longer a need for any visible other to whom we confess ourselves. Rather, we have become our own confessors (Fejes 2008b; Fejes and Dahlstedt 2012).

The message conveyed by the coach is familiar from a number of other practices, not least the recent education policy discussion on 'lifelong learning' in Sweden, within the EU and also in other parts of the world (Fejes and Nicoll 2008). In order to achieve success - as parents, children and future citizens - you need constantly to 'reinvent yourself', to be 'in step with the times', to be prepared to adapt to the demands of the situation. 'The new citizen is required to engage in a ceaseless work of training and retraining, skilling and reskilling, enhancement of credentials and preparation for a life of incessant job seeking: life is to become a continuous economic capitalization of the self' (Rose 1999, 161). Life in this 'advanced liberal family' (Donzelot 1977, 228) thereby appears to consist of one long process of selfbecoming, a lifelong learning process (cf. Assarsson and Aarsand 2011). The point of departure for the tips and advice given by the coach is that it is the individual parents who need to 'reinvent' or adapt themselves, not society (Morreale 2007). Moreover, as we have illustrated in our analysis, the shaping of good parents is conducted in the name of entertainment through the medium of reality TV. Thus, even though educational programs for parents are free and voluntary, they only attract a small fraction of all parents (cf. Widding 2011). Nanny TV, on the other hand, involves many parents, the majority of whom, most likely, do not think of themselves as participating in an educative process towards becoming a better parent. Thus, these kinds of programmes are positioned as persuasive practices through which citizens are shaped and fostered, and the programmes, therefore, require further scrutiny.

The principle of freedom of choice is something of a condition of contemporary existence, albeit one that is full of contradiction: "modern individuals are not merely "free to choose", but obliged to be free, to understand and enact their lives in terms of choice' (Rose 1999, 87). With the help of the rationality of the token economy - choose correctly and do the right thing - a pattern of living is staged that proceeds in its entirety from this principle of (un)freedom to choose. In this way, responsible parenting, active parenting, becomes the same as supporting children to become citizens who carve out their lives on the basis of the principle of choice. Laurie Ouellette and James Hay (2008, 3), make the same kind of argument about reality TV in general: 'The citizen is now conceived as an individual whose most pressing obligation to society is to empower her or himself privately'. In this responsibilising manner, parents are responsible when they raise their children to view themselves and their lives in the following way. Life is what you yourself make of it. Don't let others control you. Make your own choices. You earn your rights. In accordance with the principle of (un)freedom, everyone has the potential to succeed, all you have to do is help yourself and realise your own inner potential (cf. Winslow 2010). Those who choose not to make active choices, however, who are not capable of realising and taking the long-term consequences of their choices into consideration, are doomed to failure and - in the final analysis - only have themselves to blame. This is the ultimate consequence of the rationality of the token economy.

\section{References}

Andrejevic, M. 2004. Reality TV. Lanham: Rowman \& Littlefield.

Aslama, M., and M. Pantti. 2006. Talking alone. European Journal of Cultural Studies 9: $167-84$.

Assarsson Aarsand, L. 2011. Parents, expertise and identity work. Pedagogy, Culture and Society 19: 435-55.

Assarsson, L., and P. Aarsand. 2011. How to be good. Studies in the Education of Adults 43: 78-92.

Besley, T., and M. Peters. 2007. Subjectivity \& truth. New York: Peter Lang. 
Bratich, J.Z. 2007. Programming reality. In Makeover television, ed. D. Heller, 6-22. London: I.B. Tauris.

Cruikshank, B. 1999. The will to empower. Ithaca: Cornell University Press.

Dahlstedt, M. 2009a. Parental governmentality. British Journal of Sociology of Education 30: 193-206.

Dahlstedt, M. 2009b. Aktiveringens politik. Malmö: Liber.

Danielsen, H. and Mühleisen, W. 2009. Statens parkurs Godt liv. Tidsskrift for samfunnsforskning 50: 3-26.

Donzelot, J. 1977. The policing of families. London: John Hopkins Press.

Fejes, A. 2011. Confession, in-service training and reflective practices British Educational Research Journal 37: 797-812.

Fejes, A. 2008a. What's the use of Foucault in research on lifelong learning and postcompulsory education. Studies in the Education of Adults 40: 7-23.

Fejes, A. 2008b. To be one's own confessor. British Journal of Sociology of Education 29: 653-64.

Fejes, A. and Dahlstedt, M. 2012. The confessing society. London: Routledge.

Fejes, A. and K. Nicoll, eds. 2008. Foucault and lifelong learning. London: Routledge.

Fejes, A. and K. Nicoll. 2010. A vocational calling. Pedagogy, Culture \& Society 18: 353-70.

Foucault, M. 1988. Technologies of the self. In Technologies of the self, ed L. H. Martin, H. Gutman and P. H. Hutton, 16-49. London: Travistock.

Foucault, M. 1998. The will to knowledge. London: Penguin Books.

Foucault, M. 2003. The subject and power. In The essential Foucault, ed. P. Rabinow \& N. Rose, 126-44. New York: The New Press.

Foucault, M. 2007. Security, territory, population. Houndmills: Palgrave Macmillan.

Furedi, F. 2004. Therapy culture. Routledge: London.

Gillies, V. 2005. Meeting parents' needs?. Critical Social Policy 25: 70-90.

Gleichmann, L. 2004. Föräldraskap mellan styrning och samhällsomvandling. Stockholm: HSL.

Heyes, C. J. 2007. Cosmetic surgery and the televisual makeover. Feminist Media Studies 7: $17-32$.

Illouz, E. 2003. Oprah Winfrey and the glamour of misery. New York: Columbia University Press.

Johansson, T. 2006. Makeovermani. Stockholm: Natur och kultur.

Johansson, T. 2007. Experthysteri. Stockholm: Atlas.

Lewis, T. 2008. Smart living. New York: Peter Lang.

Livingstone, S.M. 1993. Talk on television. Florence: Routledge.

Lunt, P. 2008. Little angels. Continuum 22: 537-46.

Morley, D. 1986. Family television. London: Comedia.

Morreale, J. 2007. Faking It and the transformation of identity. In Makeover television, ed. D. Heller, 95-106. London: I.B. Tauris.

Olssen, M. 2008. Understanding the mechanisms of neoliberal control. International Journal of Lifelong Education 25: 213-30

Ouellette, L. and Hay, J. 2008. Better living through reality TV. Malden: Blackwell.

Palmer, G. 2003. Discipline and liberty. Manchester: Manchester University Press.

Palmer, G. 2004. 'The new you'. In Understanding reality television, ed. S. Holmes and D. Jermyn, 173-190. London: Routledge.

Popkewitz, T.S. 2003. Governing the child and the pedagogicalization of the parent. In Governing children, families and education, ed. M. Bloch, et al., 35-61. New York: Palgrave Macmillan.

Rose, N. 1989. Governing the soul. London: Routledge. 
Rose, N. 1999. Powers of freedom. Cambridge: Cambridge University Press.

Simons, M. \& Masschelein, J. 2008. The governmentalization of learning and the assemblage of a learning apparatus. Educational Theory 58: 391-415.

Taylor, L. 2002. Gardening lifestyle television from ways of life to lifestyle. European Journal of Communication 17: 479-493.

Widding, U. 2011. Transform your child's behaviour now. Contemporary Issues in Early Childhood 12: 252-61.

Winslow, L. 2010. Conforting the confortable. Critical Studies in Mass Communication 27: 267-90. 